Quevedo E. et al. (eds.) 'La salud pública importada (1948-1957)' y 'La salud y el desarrollo (1958-

1990 1974)'. En La salud en Colombia: un análisis socio-bistórico. Bogotá, Ministerio de Salud, pp. 38-71.

Lecturas complementarias

Duarte, Everardo

Nunes

1994

Illanes, María Angélica

1993

Nájera, José A.

1991

Wainerman, Catalina y Binstock, Georgina (eds.)

1993
'Contribuciones de Juan César García a las ciencias sociales en salud'. En J. C. García, Pensamiento social en salud en América Latina. Washington, OPS/ McGraw-Hill, pp. xiii-xxix.

En el nombre del pueblo, del Estado, y de la ciencia: bistoria social de la salud píblica, Cbile 1880-1973. Santiago, Colectivo de Atención Primaria.

'El paludismo y las actividades de la Organización Mundial de la Salud'. Boletin de la Oficina Sanitaria Panamericana, 111: 131-51.

'Origen histórico de la enfermería en la ciudad de Buenos Aires'. En Ocupación y género: mujeres y varones en enfermería. Buenos Aires, CENEP, pp. 9-29.

\section{OSWAIDO CRUZ: UM MITO DA CIÊNCIA BRASILEIRA}

\section{Nara Brito}

Rio de Janeiro, Fiocruz, 1995.

O momento não poderia ser mais oportuno. Nunca, em nosso país, o interesse do público por uma literatura do tipo biográfico foi tão grande. É claro que tal fenômeno, manifesto no sucesso de vendagem de algumas obras e no patrocínio de editoras ainda durante a elaboração dos livros, não é exclusivamente nacional. Em todo o mundo, este tipo de produção tem envolvido nomes respeitáveis da literatura, do jornalismo e do mundo acadêmico, revelando a diversidade de formas que um tal esforço pode envolver. No caso do Brasil, basta que se recorde a boa acolhida de Olgae, em 1994, de Chatô: o rei do Brasil, ambos de Fernando Morais, além de $O$ anjo pornográfico: a vida de Nelson Rodrigues, de Ruy Castro. A própria polêmica sobre direitos autorais que tumultua a comercialização do último livro deste autor, Estrela solitâria: um brasileiro chamado Garrincha, só virá pôr mais lenha no interesse do grande público leitor. Finalmente, o destaque conseguido, em 1995, pelo Quase memória, quase romance de Carlos Heitor Cony, narrando, entre realidade e ficção, a vida de seu pai jornalista, demonstra a vitalidade do 'gênero bio- gráfico' e as novas e diferenciadas modalidades em que tem sido cultivado.

E quais seriam as razões para tão amplo sucesso, sobretudo se atentarmos que livros de memórias e biografias são um tipo de literatura bem antigo e conhecido, tendo, inclusive, caído em um certo limbo de atenção por parte do público, dos escritores e das editoras, por um bom período de tempo? Acredito que inúmeras poderiam ser as respostas, mas, no que diz respeito a esta resenha, me interessa destacar as transformações que marcaram o campo acadêmico nas áreas da história e das ciências sociais, com a crescente desconfiança e flexibilização dos paradigmas de ordem estrutural, que 'expulsaram' o indivíduo para 'fora' da narrativa. Ou seja, é o retorno do ator, em especial do ator individual, reconhecido como instância de decisão (sempre há escolhas) e como rico fio condutor para o conhecimento de contextos históricos, que fez renascer não só um novo interesse pelo político e pelo cultural, como permitiu um verdadeiro boom na produção de memórias e biografias. Estas não têm mais as características laudatórias tão comuns ao gênero, e mesmo quando o 'biografado' é o próprio autor do texto, guardam um certo cuidado para não cair em exageros comprometedores.

Como se tem observado, esta produção de textos pode compreender romances ou quase romances; memórias ou quase memórias; biogra- 
fias e autobiografias, além de biografias coletivas; e pode igualmente ser construida a partir da análise de relatos biográficos redigidos pelo personagem ou por outros. Nesse último caso, por exemplo, questões metodológicas que dizem respeito a fontes estão no coração do trabalho, ai ressaltando, de forma crescente, a execução de entrevistas de história de vida, tanto para complementar a biografia que está sendo construída, como para se constituir no próprio texto do relato autobiográfico. O livro de Roberto Campos, Lanterna de popa, também muito saudado, é paradigmático, pois seria outro texto se, a certa altura de sua produção, nele não tivessem participado entrevistadores do Centro de Pesquisa e História Contemporânea do Brasil (CPDOC) municiados de questões que certamente orientaram a navegação e contribuíram para a chegada a porto seguro.

O livro de Nara Brito, não sendo uma biografia, insere-se na categoria de textos elaborados a partir de um conjunto de biografias, no caso de Oswaldo Cruz, e também de uma vasta bibliografia contento artigos, necrológios, biocronologias e até uma história em quadrinhos. Este é, aliás, um dos grandes méritos do livro: a cuidadosa e adequada seleção de fontes, que são tratadas com competência e sensibilidade. Trata-se, portanto, de refletir sobre o processo de construção da biografia de um cientista, em um certo momento e contexto, de forma a compreender como ele veio a se tornar um mito da ciência brasileira.

Este é, a meu juízo, o grande atrativo e valor do livro. O recorte realizado na problemática biográfica, que destaca com precisão as questões a serem investigadas: quando, por que, em que circunstâncias e com que objetivos esta construção mítica foi empreendida. A autora, que não casualmente é conhecedora e praticante da metodologia da história oral, investe seus esforços, com sucesso, na busca de respostas para todas estas interrogações. Fazendo-o, consegue não apenas demonstrar a não 'naturalidade' do mito, como igualmente seu poder integrador e mobilizador, sem dúvida próprio a estes construtos do imaginário social.

Ao longo de quatro capítulos, escritos originalmente como dissertação de mestrado em sociologia na Universidade Federal do Rio de Janeiro (UERJ), Nara traça um vivo painel do contexto de uma época - as décadas de 1910 a 1920 - e da situação em que se encontrava o campo científico da medicina no Brasil. Ela mostra que foi concentradamente após a morte de Oswaldo Cruz, em 1917, que seus discípulos (mas não apenas eles) lançaram-se ao culto de sua memória, que passa a simbolizar não só a instituição que dirigia, como igualmente todo um amplo projeto político-científico de luta pelo sanitarismo.

Neste momento, a imagem de Oswaldo Cruz foi apropriada por um grupo de médicos, que através dela procuravam superar as dissensões existentes no campo da medicina social, legitimando uma organização, sintomaticamente criada em 1918: a Liga Pós-Saneamento do Brasil. A liga, que atuava como um movimento político extremamente mobilizador, vinha sensibilizando setores crescentes das camadas urbanas, como estudantes, políticos, intelectuais e profissionais liberais. $\mathrm{O}$ culto à memória de Oswaldo Cruz, se nasceu de forma razoavelmente espontânea entre os médicos, foi ganhando caráter cada vez mais estruturado, o que se traduz pela dimensão institucional que o movimento sanitarista ganha ao se organizar a liga, cujo patrono é o grande cientista.

Nesse sentido, o mito pode ser avaliado como tendo imediata eficácia, pois o discurso sanitarista ecoa fundo na sociedade da época, revelando que havia uma real comunidade de sentido entre suas idéias e o contexto histórico mais amplo, marcado pelas denúncias ao não-intervencionismo do Estado e ao despreparo das elites políticas 'profissionais'. Assim, se todas as propostas da liga não são completamente implementadas, como a de criação de um Ministério da Saúcle, são parcialmente executadas - é formado o Departamento Nacional de Saúde Pública -, além de deixarem raízes no que se refere à caracterização política e à crítica oligárquica.

Embora a autora não desenvolva este aspecto, é nítido como o discurso sanitarista e o mito de Oswaldo Cruz estão associados a toda uma produção intelectual que se desenvolve a partir de então e que insiste na necessidade de 
um Estado forte e intervencionista, o que Bolivar Lamounier desginou como "ideologia de Estado". Ou seja, o discurso mítico que constrói um herói para a ciência no Brasil é também um discurso político de seu tempo, que elabora e propõe para a nação uma espécie de "teoria higienista do desenvolvimento", onde os médicos têm papel burocrático essencial.

Emoldurando esta e outras falas está o crescente nacionalismo que agita as elites políticas e intelectuais do país, voltadas para a mobilização das camadas urbanas, através de uma série de iniciativas como conferências, passeatas, meetings etc.

Mas os esforços na elaboração do mito de Oswaldo Cruz, como todos os esforços deste tipo que têm bom termo, produzem um certo deslizamento da figura do herói (real ou fictício) de 'seu' tempo de 'origem', de seu contexto e dos objetivos mais imediatos de sua construção. A grande força do mito está exatamente em combinar ficção e realidade e em lançar o herói em um tempo a histórico, podendo ele percorrer passado, presente e futuro, traçando entre eles vínculos e podendo ser permanen-temente relido e interpretado. A força do mito está em sua permanência, inseparável de sua polissemia.

Certamente por isso, como a autora destaca, à medida que o tempo "passa" (ele "passa" para os mitos?), isto é, que nos afastamos do momento datado da construção mítica original, os graus de enaltecimento - de idealização - do herói tendem a diminuir. Ela demonstra como, no caso de Oswaldo Cruz, ocorre uma aproximação mais 'realista' da biografia do homem-mito, à proporção que nos deslocamos da clécada de 1910 para a de 1950. Contudo, ela também adverte para a permanência do discurso mítico e para a conquista da vida eterna, através da materialização de valores e idéias compartilhado por uma sociedade, e que, como tais, têm longa duração. O livro de Moacyr Scliar, Sonhos tropicais, publicado em 1992, retomando a trajetória de Oswaldo Cruz, é prova eloqüente do fato, inserindo-se na onda biográfica referida no início da resenha.

Por fim, certamente o livro não seria tudo o que é se não refletisse o trabalho coletivo de um grupo - o da Casa de Oswaldo Cruz - e de uma instituição de renome - a Fundação Oswaldo Cruz (Fiocruz) - , que a postou na não separação entre ciências sociais e biológicas, já que, afinal, como sabemos, mas esquecemos, o homem é um animal que só vive em sociedade. A própria bibliografia do volume, com inúmeras citações de textos produzidos e editados pela Fiocruz, é testemunho deste longo investimento que ainda dará numerosos frutos.

Angela de Castro Gomes Professora Titular do Departamento de História da Universidade Federal Fluminense. Rua Santo Inácio, 36 Niterói — RJ 24370-580 